\title{
COMUNICAÇÃO POLÍTICA E CORRUPÇÃO
}

\author{
Political communication and corruption
}

\begin{abstract}
Fernando Filgueiras
Doutor em Ciência Política pelo Instituto Universitário de Pesquisas do Rio de Janeiro (IUPERJ). Pesquisador Associado do Centro de Referência do Interesse Público da Universidade Federal de Minas Gerais (UFMG). Belo Horizonte, MG - Brasil, email: fernandofilgueiras@hotmail.com
\end{abstract}

\section{Resumo}

Este artigo é um exercício reflexivo a respeito da relação entre comunicação política e corrupção. O artigo tem o objetivo de formular alguns apontamentos teóricos a respeito de como foi nomeado o problema da desocultação da corrupção na política. Partindo da teoria do campo de Pierre Bourdieu e da ética do discurso de Jürgen Habermas, o artigo aponta para o modo como é construída a comunicação política e as representações a respeito do fenômeno da corrupção na política. $\mathrm{O}$ artigo problematiza a questão da comunicação política nas democracias contemporâneas, no que tange ao problema da corrupção, apontando para uma gradativa tendência de crises políticas que mina a legitimidade da ordem democrática.

Palavras-chave: Corrupção; Comunicação política; Escândalos; Legitimidade.

\begin{abstract}
This article is a reflective exercise regarding the relation between political communication and corruption. The article has the objective to formulate some theoretical notes regarding what I nominate as problem of the revelation of the corruption in the politics. Leaving of the theory of the field of Pierre Bourdieu and the ethics of the speech of Jürgen Habermas, the article points with respect to the way as politics is constructed to the communication and the representations regarding the phenomenon of the corruption in the politics. The article points the problem of the question of the political communication in the contemporaries democracies, in what it refers to the problem of the corruption, pointing with respect to a gradual trend of crises politics that the legitimacy of the democratic order.
\end{abstract}

Keywords: Corruption; Political communication; Scandals; Legitimacy. 


\section{INTRODUÇÃO}

De uma perspectiva quase que de senso comum, a corrupção significa a sobreposição dos interesses privados ao interesse público. Essa é uma forma abrangente de se conceituar a corrupção, de maneira que esta asserção abarca um conjunto de práticas que podemos nomear como corrupção. Nepotismo, clientelismo, patronagem, desvio de recursos públicos, fraudes e todo o tipo de desonestidade do homem público podem ser nomeados como corrupção. Dessa forma, o conceito de corrupção é impreciso no que diz respeito à sua realidade empírica. Múltiplas práticas sociais e políticas podem ser nomeadas como corrupção, de modo que o conceito se apresenta de forma árida aos instrumentais da ciência política e da sociologia.

Fundamentalmente, o conceito de corrupção tem uma dependência normativa, em que seu significado depende de concepções de valores e normas consensuais, que nascem de um processo deliberativo no âmbito da esfera pública. Ou seja, só é possível compreender o que é ou o que não é corrupção quando há valores e normas pressupostos, que são resultado de concepções morais da política, que espelham os processos de deliberação pública. Dessa forma, o significado da corrupção expressa acordos normativos que tem origem nos processos comunicacionais da política. O significado da corrupção, portanto, depende de um processo discursivo que mobiliza a moralidade e a expressa na forma de juízos acerca da ordem política e da ação de seus agentes.

Se seguirmos a orientação conceitual dos interesses, a aridez com que o tema da corrupção é apresentado na esfera pública afeta uma compreensão geral do problema na política. Uma forma alternativa de compreensão do fenômeno da corrupção, no entanto, é abordá-lo como uma expressão linguística de juízos morais. De maneira cética, é possível afirmar que a corrupção não tem uma natureza empírica. Ela é subliminar na política, de maneira que torna difícil uma medida efetiva do tamanho da corrupção na política. Se abordarmos a corrupção como discurso, por outro lado, é possível pensar as consequências e o processo social que delimita sua abrangência na sociedade e na política (FILGUEIRAS, 2007a).

Como expressão de um juízo moral, seguindo uma orientação habermasiana da teoria da ação comunicativa, a corrupção está relacionada aos processos de comunicação política, em que ela se apresenta de maneira flexível e plástica na esfera pública, de acordo com os critérios morais dos valores e normas que organizam a vida política. A corrupção pode ser melhor compreendida como uma forma de discurso político, em que atores mobilizam a moralidade política de forma a relacionar valores e normas às práticas inerentes ao campo político. Como expressão de juízos morais, a corrupção só pode ser enunciada discursivamente em uma situação ideal de fala, em que a imparcialidade seja um procedimento fundamental à política. Todavia, no mundo prático, não é isso o que ocorre. No mundo prático da política, a corrupção é desocultada a partir de fins instrumentais dos atores, em que o desvelamento dela depende dos interesses de seus intérpretes.

Este artigo tem o objetivo de fazer uma reflexão a respeito da relação entre comunicação política e corrupção, apontando os problemas decorrentes do modo como a corrupção é abordada no discurso político, conforme aquilo que chamamos de problema da desocultação da corrupção. Não trataremos dos valores e normas que organizam os discursos dos atores, mas da prática comunicacional da desocultação da corrupção nas democracias. Argumentaremos que o modo como a corrupção é desocultada na esfera pública acarreta problemas de legitimação política nas ordens democráticas, fazendo com que haja uma tendência de crises políticas permanentes na esfera pública. As delinquências do homem público são abordadas em um discurso político instrumental, voltado para o escândalo e para a moralização da política, que a deslegitima e a acomete de uma visão comum como o espaço dos vícios, onde a corrupção é a regra e não a exceção.

$\mathrm{O}$ artigo está dividido em três seções. $\mathrm{Na}$ primeira seção trato do problema da desocultação da corrupção nos processos comunicacionais da política, seguindo uma orientação habermasiana da teoria dos atos de fala. Mostro como a forma mediante a qual a corrupção é desocultada tem uma pretensão de ser um discurso verdadeiro por parte da comunidade dos intérpretes. $\mathrm{Na}$ segunda seção serão analisadas as representações sociais e os processos envolvidos no campo político, associando o discurso de desocultação da corrupção com a construção simbólica do espaço da política, a partir da teoria do campo de Bourdieu. $\mathrm{Na}$ terceira seção, que finaliza o artigo, apresentamos alguns apontamentos a respeito do problema da desocultação da corrupção nos processos de comunicação política. 


\section{A desocultação da corrupção}

De uma perspectiva cética, a corrupção é um tipo de força oculta da política, porque está em uma posição liminar, representando um fenômeno ubíquo, que se realiza na política, e, ao mesmo tempo, fora dela (LESSA, 2003, p. 116). Ou seja, a corrupção é algo oculto na política, que tem suas bases em torno do segredo e dos esquemas que ultrapassam as fronteiras morais da política. Por se tratar de algo subliminar, a corrupção está oculta na política, funcionando como um tipo de prática que não é aparente e muito menos sujeita a punição, caso seja bem sucedida. É por isso que não é possível uma medida empírica eficaz da corrupção, porque a corrupção que se conhece é aquela que é mal sucedida.

Mas o fato de a corrupção estar oculta na política não impede o fato de ela poder serdesocultada. A desocultação é um tipo de problema inerente às democracias representativas contemporâneas, que assentam o problema da corrupção em discursos políticos com pretensão de validade, porquanto representem discursos assertóricos sobre uma realidade empírica da corrupção. A desocultação é a produção de discursos com a pretensão de serem verdadeiros, que estão assentados em rotinas próprias do mundo político, por meio das quais a corrupção deve ser controlada e combatida. A desocultação é uma modalidade de produção da verdade em política, quando a corrupção se torna aparente. Significa a produção de discursos assentada em proposições assertóricas, que são empregadas intencionalmente e estruturam uma atividade orientada a fins (HABERMAS, 2004, p. 111).

A desocultação da corrupção, por ser um discurso assertórico sobre sua realidade empírica, é realizada por uma comunidade dos intérpretes da corrupção. A comunidade dos intérpretes da corrupção constrói discursos assertóricos a respeito de sua realidade e se colocam como atores da cena política, em que a corrupção é desocultada ao público por meio de discursos que tem uma natureza moralizante. Basicamente, são três os atores envolvidos no problema da desocultação da corrupção, ou seja, que enunciam esses discursos assertóricos a respeito da corrupção na política. Primeiramente, a própria esfera de representação política no plano dos partidos e das demais instituições políticas. Em segundo lugar, a opinião pública influenciada pela mídia. E, finalmente, o Direito e seus procedimentos.
No caso dos dois primeiros atores, eles agem no mesmo contexto da política, em que a lógica do escândalo é resultado dos discursos assertóricos, orientados aos fins. O Direito, por outro lado, apresenta-se ao público como narrador imparcial. Estes atores compõem campos diferentes de atuação; isto é, atuam em espaços da política, que circunscrevem práticas e visões de mundo diferenciadas, que influenciam o modo como se constrói o juízo acerca da corrupção na política. Neste artigo, não trataremos da questão dos processos comunicacionais do Direito e, portanto, nos restringiremos à análise da corrupção como discurso na esfera dos políticos profissionais e da opinião pública.

O fato é que delimitar o que é e o que não é corrupção depende, em grande medida, das estruturas comunicacionais da política, em que partidos e mídia influenciam o modo como se constrói a realidade e as representações sociais a respeito da política. E o modo como essa realidade e essas representações são construídas comunicativamente estipulam a forma como são organizados os mecanismos de controle da corrupção (FILGUEIRAS, 2006). O controle e a punição aos casos fracassados de corrupção passam, necessariamente, por mecanismos de construção de discursos que pretendem ser verdadeiros na política. A desocultação é a produção de discursos com pretensão de verdade, em que eles estão sujeitos a seu uso instrumental por parte dos atores do campo político.

Por se tratar de um ato de fala representativo, a desocultação depende de quem o enuncia. Existe um plano linguístico em que a estratégia domina os meios pelo qual a verdade será produzida, tratandose de uma modalidade de discurso político ligada a um tom matizado de revelação da corrupção à opinião pública. Como verdade factual, a desocultação está ligada ao mundo da doxa, em que a aparência importa mais que a essência; sendo uma modalidade de discurso pelo qual importam formas como reputação, carisma e capacidade de liderança do político. Isso se deve, de alguma maneira, à diferenciação da mídia e à produção da opinião pela indústria cultural, de acordo com um discurso instrumentalizado e não orientado para o entendimento (HABERMAS, 2003).

No mundo contemporâneo, a crise do modelo de representação política acarreta, com relação ao tema da corrupção, um tipo de problema em que a responsabilidade depende de sistemas de 
desocultação. Um dos elementos fundamentais para a instituição de uma ética de responsabilidade, própria ao mundo da democracia representativa, está na construção da verdade na política. ${ }^{1}$

A responsabilidade política depende de sistemas de construção da verdade, relacionados a uma lógica de controle da corrupção. No caso da corrupção, esses sistemas de construção da verdade factual, no mundo contemporâneo, passam por uma lógica de desocultação, a qual tem um processo específico na arena política. Por se tratar de discursos com pretensão de validade, eles podem ser verdadeiros ou falsos. Isso não significa que opiniões ou convicções morais sejam sempre verdadeiras. Quem compartilha, do mesmo modo, uma concepção falsa não é, necessariamente, irracional.

A especialização técnica e profissional da política acarretou um processo em que a corrupção pertence as rotinas da burocracia do Estado e dos partidos políticos, respeitando o processo de racionalização próprio à modernidade capitalista (WEBER, 2002). Desse modo, ela é inerente ao cotidiano dos sistemas administrativos, porquanto o dinheiro e a competição pelo voto demandam a criação de sistemas de arrecadação de fundos de campanha e posterior distribuição dos espólios. A corrupção, ao se tornar cotidiana na vida burocrática, relaciona-se com um mundo técnico, ditado especialmente pelo Direito e seus procedimentos. Em que medida a corrupção avançou ou regrediu, não é possível afirmar, mas o fato é que a corrupção que se conhece está relacionada a esquemas que não deram certo e, por tal característica, será passível de punição por parte de sistemas especializados ditados pelo Direito.

Nas democracias contemporâneas, a ineficiência dos mecanismos de responsabilização, no interior dos órgãos burocráticos do Estado e dos partidos políticos, implica um processo em que a desocultação é um tipo de discurso inerente à corrupção na política. Ou seja, um processo de comunicação política marcado pela disputa em torno da verdade da corrupção, de acordo com fins instrumentais no interior da esfera pública. Os casos de corrupção que emergem a esfera pública estão sujeitos a essa modalidade de discurso, que pretende produzir verdade, de acordo com a prática do escândalo. Esse fenômeno deriva do fato de os sistemas administrativos produzirem um distanciamento em relação à esfera pública, o que, de acordo com Habermas, significa a produção de sua legitimidade ao mesmo tempo em que ocorrem processos de crise de legitimação (HABERMAS, 2002).

O resultado é uma crescente instrumentalização do discurso político, que por se constituir de atos de fala representativos, tem a pretensão de serem verdadeiros. Em outras palavras, a corrupção se torna algo fundamental no discurso político, no interior das democracias contemporâneas, porquanto a histeria ética se tornou elemento central nas relações de poder entre os agentes e os partidos. A corrupção configura um processo em que a crise de legitimação da democracia promove a permanência da lógica de sua desocultação, reforçando uma tendência permanente de crises políticas. Isto é, a política passa a ser vista como império dos vícios, onde a corrupção é a regra fundamental.

Do ponto de vista da democracia, esses discursos tornaram-se comuns. Como se trata de discursos representativos, a audiência não tem meios de controle se a pretensão do discurso é verdadeira ou falsa. O problema da desocultação é o fato de esses discursos assertóricos estarem na base de atos de fala afirmativos, sem que o resultado seja a responsabilidade, mas a gradativa penalização do mundo político. ${ }^{2} \mathrm{O}$ problema da desocultação é que o discurso que pretende ser válido a respeito da corrupção está entregue a atores sociais nem sempre dotados da plena legitimidade para proferilos. Como são discursos com pretensão de verdade, ocorre uma precipitação do juízo, que nem sempre resulta em responsabilidade do corpo político.

\footnotetext{
1 A respeito da ética de responsabilidade, conferir WEBER, M. A política como vocação. In: GERTH, HANS, H.; MILLS, C. W. (Org.). Ensaios de sociologia. Rio de Janeiro: LTC, 2002. p. 325-328.

2 Sobre a crescente visão da política mediante o Direito Penal, conferir GARAPON, Antoine. O juize a democracia. Rio de Janeiro: Revan, 2001. Para este autor, existe nas democracias contemporâneas um processo de judicialização da política, em que o mundo político assume cada vez mais os rituais e procedimentos do mundo judiciário. Exemplo dessa asserção é a realização de Comissões Parlamentares de Inquérito (CPI's), que deixou de ser um mecanismo de controle do Legislativo sobre o Executivo para se tornar uma espécie de tribunal político penal.
}

Rev. Estud. Comun., Curitiba, v. 9, n. 19, p. 77-87, maio/ago. 2008 
A corrupção, uma vez desocultada por esses discursos assertóricos, não implica a construção da responsabilidade, mas de uma lógica assentada no escândalo e no esquecimento coletivo.

Como uma forma de discurso que tem a pretensão de validade acerca da corrupção, a desocultação torna-se um discurso permanente nas democracias contemporâneas, acarretando um processo de histeria ética que agrava as crises de legitimação. Isso passa, necessariamente, pela instrumentalização do discurso político, cujo fim não é a produção de consensos normativos no plano da sociedade, mas o fortalecimento das relações de poder e o conflito político. Como doxa, a desocultação é a produção de verdade factual a respeito da corrupção, cuja resultante, nas democracias contemporâneas, é a instauração de um sentimento de crise ética, associado ao mau funcionamento do sistema político, fazendo com que a apatia e a indiferença sejam a tônica do comportamento político. Isso se deve ao fato de a desocultação tratar-se de um discurso marcado por hipérboles, destinado a aumentar ou diminuir a verdade da corrupção.

É nesse sentido que a transparência se torna um mito com relação ao controle da corrupção. A diferenciação do sistema político implica a construção de uma linguagem técnica, em que aquilo que é transparecido é controlado sistemicamente. Como pretensão de verdade, a corrupção pode ser mantida oculta, ou desocultada, acarretando os efeitos perniciosos sobre a ordem. A transparência das instituições políticas, nesse sentido, pode ser danosa ao Estado e à república; pelo motivo de que o domínio da opinião, próprio da esfera pública, não consegue julgar, eficazmente, a ação política, visto que se trata de discursos instrumentalizados com o fim de angariar poder. $\mathrm{O}$ político pode agir de maneira responsável se ocultar a corrupção aos olhos da esfera pública. Nem sempre, portanto, a comunicação política pode ser transparente frente ao público, visto que a responsabilidade nem sempre depende da verdade, no sentido da política.

No liberalismo contemporâneo, o conceito de transparência se tornou primordial na política. Ele pressupõe que a política deve se submeter à percepção que eleitores e contribuintes tem das políticas públicas conduzidas pelo Estado. O conceito de transparência, em primeiro lugar, aponta para uma visão restrita da cidadania, criando uma miopia em relação às demandas republicanas e comunitárias. E, em segundo lugar, do conceito de transparência não se deriva uma concepção substantiva de interesse público, com a qual se possa criar mecanismos eficazes de controle da corrupção. O conceito de transparência faz com que a corrupção apenas se torne aparente e submetida ao processo de desocultação, tão em voga na política contemporânea.

Aquilo que é desocultado, ou transparecido, pode se transformar em denúncia moral e não em responsabilidade perante o juízo da esfera pública. O denuncismo moral anula qualquer possibilidade de debate público acerca da corrupção, visto que as idéias reitoras do verdadeiro ocultamse na obviedade de uma realidade comum, tendo em vista uma histeria ética. Ou seja, o entendimento dá lugar à estratégia, de modo que a desocultação colabora para sua (re)ocultação. Como a corrupção é um problema político de primeiro plano, a ausência de entendimento acerca de seu alcance e de sua prática vela seu real alcance. Aquilo que é transparecido não significa uma verdade no sentido epistêmico, mas uma proposição enunciada de acordo com um ato de fala representativo. A transparência, nesse sentido, não implica, necessariamente, em responsabilidade; mas na exclamação de discursos de desocultação que pretendem ser verdadeiros, mas que podem ser falsos à medida que não precisam apresentar uma base de justificação.

Uma vez que a corrupção é sempre desocultada, o modo como ela se torna verdadeira depende do uso público que os homens fazem da razão. Uma vez desocultada, não é possível distinguir se o alcance da corrupção é verdadeiro ou falso, visto que ela representa a instrumentalização da comunicação política, esvaecendo, dessa forma, qualquer possibilidade de produção da verdade. A revelação da corrupção termina por ser mais o denuncismo moral do que o alargamento do debate de seus efeitos. A corrupção tem a faceta de, normalmente, se transformar em escândalo, cujo efeito é mais se (re)ocultar do que se tornar aparente. $\mathrm{O}$ campo político tem a peculiaridade de transformar a corrupção em escândalo, uma vez que se sustenta na doxa. A conclusão, seguindo a trilha de Hannah Arendt, é que a verdade, nesse caso a verdade da corrupção, deve ser revelada fora do domínio político, pelo motivo de que sua enunciação exige imparcialidade e desinteresse (ARENDT, 1972, p. 324). 
Mesmo que a verdade não seja uma exigência da política, o fato é que ela pretende se tornar um processo próprio ao campo político, quando diante de casos revelados de corrupção. A desocultação é inerente ao momento em que a corrupção se torna aparente ao público, perdendo seu traço de ubiquidade e segredo, para se converter em escândalos, especialmente no contexto da crise do modelo de representação na democracia. A corrupção revelada ao público, sem se ater a qualquer concepção pura de verdade, perde, nesse sentido, seu poder coercitivo que nem sempre se converte em responsabilidade, via Direito.

O fato é que a desocultação tornou-se um problema inerente às democracias representativas, uma vez que, diante dos casos de corrupção na política, não se consegue converter o discurso em responsabilidade. Se, na democracia, a corrupção deve ser desocultada fora do contexto político, com o condão de impedir o escândalo e a histeria ética, essa desocultação deve ser realizada por um narrador imparcial, com o intuito de impedir a instrumentalização do discurso. O problema é quando esse narrador imparcial é instrumentalizado pela política, acarretando um processo em que a corrupção se torna permanente, mas nunca punida.

E a lógica da desocultação que proporciona uma abrangência da corrupção em que ela se apresenta de maneira endêmica, suscetível a certa paralisia decisória. A corrupção se torna uma espécie de normalidade cotidiana da política, apesar de a sociedade tolerá-la no contexto das relações de poder. A corrupção se torna, com o problema da desocultação, inerente às democracias representativas, um tipo de endemia explorada pela histeria ética, sem alcançar resultados práticos no que diz respeito a elementos de reforma e mudança institucional. A democracia, dessa forma, fica sujeita ao gradativo descontentamento e indiferença, ampliando sua crise de legitimidade à medida da desocultação da corrupção. A política, a permanecer o problema da desocultação, passa a ser vista como o espaço dos vícios, tornando-se secundária em relação ao mundo econômico.
$\mathrm{Na}$ próxima seção, abordaremos a desocultação da corrupção no campo político e quais são as características desse processo em ambos os campos. Mostraremos como a lógica da desocultação está envolvida na produção dos escândalos, e como isso se deve ao esoterismo do modelo de representação política em relação ao cidadão comum, que produz representações a respeito da política como o espaço dos vícios, onde a corrupção impera.

\section{A comunicação política e as representações acerca da corrupção}

Seguindo uma orientação habermasiana da teoria dos atos de fala, conclui-se que a corrupção está relacionada a discursos assertóricos, baseados em atos de fala representativos, que estruturam uma atividade orientada a fins. São discursos que tem uma pretensão de verdade, mas que a audiência não tem como controlá-lo, visto que não ocorrem na base de uma justificação e aplicação de valores e normas. Operar esses discursos na base de uma sociologia política da corrupção acarreta o fato de se perceber os espaços sociais onde o problema da desocultação ocorre. Nesse sentido, é fundamental pensar os discursos assertóricos tão comuns ao problema da desocultação, bem como os espaços sociais onde esses discursos são enunciados. Dessa maneira, a teoria do campo de Bourdieu pode ser profícua à compreensão do espaço desses discursos assertóricos, ampliando a margem de aplicação da teoria dos atos de fala de Habermas. Ou seja, unir o plano do discurso às práticas inerentes a esfera política. Além da questão do discurso propriamente dito, é fundamental pensar a constituição das representações sociais da corrupção na política, conforme esferas diferenciadas de ação.

O campo político, na ótica de Pierre Bourdieu (2005), é um tipo de esfera da vida social dotada de autonomia, na qual os agentes concorrem entre si pela disputa da produção de programas, análises, conceitos e acontecimentos. Ou seja, os agentes lutam pela geração de "produtos simbólicos", dotados de uma força ideológica que permita a conquista do poder. ${ }^{3} \mathrm{Na}$ modernidade,

\footnotetext{
${ }^{3}$ Bourdieu, no que tange ao conceito de ideologia, segue uma influência marxista, ao atrelar o conceito de poder simbólico ao modo como ela representa uma cultura dominante para a integração fictícia da sociedade. No limite, o conceito de ideologia de Bourdieu expressa a força com que as idéias são capazes de criar uma falsa consciência, dotada da capacidade de desmobilização das classes dominadas para a legitimação da ordem estabelecida. A esse respeito, conferir BOURDIEU, P. A economia das trocas simbólicas. São Paulo: Perspectiva, 2001.
}

Rev. Estud. Comun., Curitiba, v. 9, n. 19, p. 77-87, maio/ago. 2008 
como apontou Bourdieu, a política é a realização de "produtos simbólicos" originados da disputa entre políticos profissionais. Esses profissionais criam representações de mundo mediante discursos passíveis de serem produzidos e reproduzidos dentro de um espaço de tomadas de posição, tendo em vista um universo de técnicas de ação e de expressão a serviço da sociedade. A disputa pelo poder ocorre, essencialmente, pela capacidade do político de gerar "produtos simbólicos", que permitam a representação permanente da política, conforme uma homologia com a estrutura do teatro político.

O desenrolar da luta no campo político, de acordo com Bourdieu, se dá na força de mobilização do vencedor frente ao grupo que reconhece as idéias produzidas, seja pela sua expressão na força de manifestação de massas, seja pelo "silêncio ou ausência de desmentido" (BOURDIEU, 2005, p. 185). O campo político, portanto, é o espaço de crenças, dotadas de uma força representativa do mundo, capaz de descrever e julgar a realidade política de maneira factual. Discursos assertóricos, baseados em atos de fala representativos, são inerentes às práticas do campo político, que é o espaço onde essa modalidade de discurso é produzida. Nesse caso, o que o campo político tem produzido é a crença de que a corrupção é endêmica nas democracias contemporâneas.

Se a política é um campo dotado de autonomia, construído em cima de conflitos específicos entre aqueles que são incluídos e iniciados no campo; o cidadão comum, que se inclui entre aqueles "de fora", está sempre sujeito a uma cultura esotérica. A política é feita de problemas e perspectivas de mundo estranhas e inacessíveis ao cidadão comum, de maneira que seus conceitos e discursos nunca estejam referidos ao vulgar, àquilo que é comum à grande maioria. $\mathrm{O}$ jogo relacional do campo político é feito de discursos destinados a deter uma verdade factual, reunindo em seu espaço social uma força simbólica capaz de torná-lo legítimo. E enquanto discurso, existem motivações de poder, que ampliam o potencial de conflito para a produção de mobilização ou de silêncio, por parte da audiência sujeita a esta cultura esotérica. Um fato não atentado por Habermas é que, na política, os atos de fala representativos dependem de quem os enuncia, ou seja, precisam da força simbólica de seu autor junto à audiência. Como são discursos com pretensão de validade, o verdadeiro depende, nesse caso, de quem está falando.
A noção de campo de Pierre Bourdieu, associada à idéia dos discursos assertóricos de Habermas, permite compreender a maneira de acordo com a qual a corrupção é desocultada no contexto político. A corrupção bem sucedida é aquela que se mantém como força oculta do campo político, tendo em vista o silêncio e o segredo que a caracteriza. A corrupção mal sucedida, entretanto, é aquela que mobiliza o discurso e fortalece a disputa pelo poder, uma vez que os diferentes agentes procuram representá-la de maneira a animar suas posições políticas; seja pela crescente mobilização dos cidadãos em torno de um denuncismo moral, seja pelo crescente silêncio, visando a reproduzir a situação do campo. O fato é que a desocultação da corrupção cria uma correlação de forças entre aqueles que preferem a crescente mobilização e aqueles que preferem o silêncio. E dessa disputa, o verdadeiro acerca da corrupção distancia-se, à medida que se torna uma disputa pelo factual da corrupção junto aos "de fora" do campo, em especial, junto à opinião pública.

Cada força do campo político procura, dessa forma, representar a corrupção de uma maneira que favoreça sua posição e a luta pelo poder, construindo discursos assertóricos dissonantes, que escamoteiam a real face da corrupção na política. Esses discursos assertóricos tem a característica de aumentar ou diminuir a verdade acerca da corrupção, porquanto buscam sua legitimidade frente à opinião pública por meio da gradativa dramatização e histeria ética. Cada força do campo político leva a desocultação da corrupção ao exagero, visando a fortalecer suas posições por meio de duas hipóteses: (1) a desocultação da corrupção, no campo político, pode resultar na construção social do escândalo político, o qual resulta na (re)ocultação da corrupção; (2) ou a corrupção pode ser (re)ocultada, de forma que a força majoritária consiga desmentir o caso pela afirmação de uma outra noção verdadeira e manter o silêncio dentro do campo político.

Enquanto escândalo político, a corrupção envolve uma infração, uma violação de regras que são denunciadas pelas forças políticas não participantes do esquema. Enquanto discurso assertórico, a linguagem do escândalo procura sua legitimação pela forma como se espalha rapidamente e de maneira incontrolável. O escândalo político depende, antes de qualquer coisa, de sua audiência (THOMPSON, 2002). O escândalo toma a forma de um discurso legitimado por parte da audiência da 
opinião pública, ditada pela mídia, junto à força antagônica àquela envolvida. Como consequência imediata, o escândalo fere a reputação dos envolvidos, permitindo ou a expulsão, ou o arrefecimento do poder dos envolvidos. Uma vez que a reputação tem uma força simbólica, como indica Thompson, ela é sempre o primeiro recurso mobilizado nos discursos dentro do campo político. O escândalo depende do conhecimento das forças antagônicas do campo político, bem como de outros campos da vida social, tornando aquilo que era segredo visível aos olhos do público.

É importante frisar que o escândalo não se resume à corrupção. Também pode se tratar de escândalos sexuais, morais, familiares e religiosos, que estejam ligados ao campo político. Entretanto, o escândalo político é uma das facetas da corrupção mal sucedida, porquanto a torna visível ao público, ou seja, desocultada. Da mesma maneira, é importante frisar que nem toda corrupção, mesmo a mal sucedida, torna-se escândalo. A medida para que a corrupção se torne escândalo depende do antagonismo das forças envolvidas dentro do campo político, bem como da disposição dessas forças em (d)enunciá-la mediante discursos assertóricos, além da disposição da própria opinião pública de se tornar audiência desses discursos. Em tese, os escândalos políticos, que envolvem a corrupção, representam sua face visível, suscetível ao poder do campo da mídia e o modo como ocorre sua cobertura. O fato é que a corrupção, quando se confunde com o escândalo, fica suscetível de ser aumentada ou diminuída, uma vez que se trata de um discurso com pretensão de validade e orientado aos fins.

A faceta visível da corrupção, sujeita aos discursos assertóricos emitidos pelas diferentes forças do campo político, implica o envolvimento de lideranças políticas, encerrando-se em uma arena de discussão na qual a luta pelo poder é o mote central do conflito. Em outras palavras, a produção da verdade factual da corrupção na política está sujeita a um uso instrumental. Cada envolvido nos esquemas de corrupção procura aumentar ou diminuir a verdade acerca deles. Aqueles que a aumentam, procuram invalidar o poder dos envolvidos, recorrendo, normalmente, ao denuncismo moral, o qual é capaz, em muitos casos, de mobilizar a massa e ferir a reputação das lideranças. De outro lado, aqueles que diminuem a verdade da corrupção na política procuram manter sua posição dentro da distribuição do poder no campo político, desmentindo ou desclassificando aquilo que está visível, ou seja, informações e imagens. O fato é que o antagonismo de forças no campo político se descontrola, de maneira a criar instabilidade e incertezas.

Como afirma Sherman, a corrupção, quando se torna escândalo político, tem diferentes estágios de desenvolvimento (SHERMAN, 1990). Em primeiro lugar, vem a revelação, que a submete ao escrutínio público. Em segundo lugar, vem a publicização e o modo como a mídia assume papel relevante na propagação do escândalo. Em terceiro lugar, vem a defesa dos envolvidos, que procuram desmentir as acusações. Em quarto lugar, o escândalo atinge seu ápice, quando se torna dramatização por parte das posições políticas contrapostas. Em quinto lugar, vem a execução, quando o escândalo se torna uma questão jurídica. E, finalmente, vem a rotulação, a qual, de alguma maneira, encerra o caso. Uma vez que o escândalo tem um desenvolvimento temporal, o resultado prático é que a corrupção (re)oculta-se no campo político, uma vez que afasta-se da verdade factual, inicialmente revelada, em tese, ao público. Como se trata de disposições do discurso assertórico, a retirada de foco termina por (re)ocultar a corrupção, na medida do interesse das forças políticas em disputa.

Como discursos que procuram representar a corrupção na política, os escândalos resultam no esquecimento coletivo, de maneira que a perda do foco (re)oculta seu epicentro dentro do próprio campo político. Mesmo que haja oposições constitutivas no campo, a corrupção é absorvida e retirada do domínio comum. Dentro dos discursos assertóricos, os escândalos de corrupção saem do campo político e retornam a ele mediante a recomposição das forças e da distribuição do poder. O esquecimento coletivo é o fato de os escândalos que envolvam a corrupção serem processados pelo campo político, de maneira que sua normalidade seja reconstruída. Ou seja, os escândalos que envolvem corrupção originam-se no campo político, mas retornam a ele mediante a subordinação à disciplina das regras do campo.

Como o cidadão comum está sujeito a uma cultura esotérica, tendo em vista um mundo especializado e técnico, quando se trata do campo político, o real alcance do escândalo de corrupção e suas consequências são sempre diminuídos. Mesmo que haja uma mobilização por parte da opinião pública, os discursos assertóricos emitidos pelos atores do campo político sempre terminam 
por escamotear a verdade, uma vez que sempre estão fora de seu alcance. Como essa linguagem não é compreensível pela audiência, o comum é que ela saia de cena, fazendo com que o campo recomponha-se ou pela antiga ou por uma nova distribuição de poder.

A verdade, como ensina Hannah Arendt, não se dá bem com a política, de forma que o campo político é o contexto menos favorável à desocultação da corrupção (ARENDT, 1972, p. 283). É fundamental perceber que a corrupção deve ser desocultada fora do campo político, porque a exigência de ação não necessariamente deve se pautar pela moralidade. Qualquer tentativa de revelar a verdade da corrupção por dentro do campo político, nesse sentido, ocorre por uma motivação de poder, conforme o fato de essa revelação se dar pela via dos discursos assertóricos, com pretensão de verdade, mas sem uma base de justificação. O fato é que, na política, jamais a corrupção será revelada, mantendo-se como força oculta, presente em sua estrutura e suscetível ao movimento de desocultação e (re)ocultamento.

O campo político esforça-se por manter a corrupção velada, como uma força oculta que estrutura a ação política. O escândalo representa a façanha do campo político em (re)ocultar a corrupção, mantendo-a permanentemente em sua estrutura, de maneira a reproduzi-la no tempo. O contexto de tolerância à corrupção ocorre em função do campo político diferenciar-se socialmente, ficando imune, de alguma maneira, ao mundo dos valores e à própria moralidade. Como o cidadão comum não consegue influir na constituição do campo político, ele tolera a corrupção, porque ela sempre se oculta dentro do campo. O cidadão comum prefere esquecê-la, visto que a arte esotérica da política tem o poder de (re)ocultar a corrupção, apesar de criar um sentimento de crise moral que se reproduz no cotidiano da cidadania.

O esquecimento coletivo da corrupção na política surge com os grandes escândalos, que convergem os atos de fala representativos em precipitação de culpa e não em responsabilidade por parte dos envolvidos. E, como tal, sustenta-se num campo de forças em disputa, cada qual querendo conquistar o poder, nem que para isso faça uso da corrupção como expediente para maximizar os meios necessários para a satisfação dos fins. Justamente por ser um discurso instrumentalizado, a corrupção se oculta porque não é passível de entendimento, no âmbito da esfera pública. Como se trata de grandes escândalos, a corrupção sempre recai no silêncio das instituições, istoé, no modo como elas são competentes para retirar do público qualquer espaço de ação, implicando um processo gradativo de crise de responsividade dasinstituições ao clamor da sociedade.

A verdade da corrupção está, consequentemente, fora do campo político. Está no modo como a corrupção e seu tratamento por parte das instituições potencializam um aprendizado moral do cidadão comum. A verdade revela-se, nesse sentido, fora do mundo dos fatos, fora da realidade concreta da corrupção, porque esta não pode ser absorvida, verdadeiramente, pelo cidadão comum. A verdade da corrupção é contrafactual porque remete a um outro mundo possível, sustentado na leitura desse mundo por critérios de correção, justificados racionalmente. Os sistemas de comunicação política podem exercer um papel primordial de controle da corrupção, se exercerem um trabalho de pedagogia cívica. Não pela lógica dos escândalos, mas por um processo de esclarecimento que se dá por sua presença na esfera pública.

O necessário é possibilitar mecanismos de entendimento e de comunicação política não enviesados pelo denuncismo moral ou pelo silêncio velado das instituições. A verdade da corrupção, nesse sentido, desoculta-se sempre em contextos democráticos significativos, que tenham a presença de um narrador imparcial e desinteressado. Mesmo que o campo político a transforme em escândalo, os contextos democráticos são capazes de colocar a corrupção em movimento, ao invés de (re)ocultá-la. Ou seja, os contextos democráticos são os únicos capazes de revelar a corrupção uma vez que mobilizam sua potência sobre a ordem, visando a transformá-la ou mesmo a corrigir seus rumos. A verdade da corrupção, mesmo que no plano contrafactual e fora do campo político, é capaz de potencializar o movimento da ordem, de maneira a exercer, nesse sentido, uma pedagogia cívica destinada a fortalecer a moralidade da política e não sua moralização.

O fato é que as instituições políticas precisam ser responsivas às demandas da sociedade, mesmo que isso implique a existência de discursos assertóricos, com pretensão de serem verdadeiros, mas que, ao mesmo tempo, também podem ser falsos. Não cabe à política o papel de narrador imparcial, porquanto seus juízos estejam assentados no plano dos interesses. As instituições políticas, em uma democracia representativa, precisam ser responsivas às demandas da cidadania. 
Isso não invalida, entretanto, o fato de que a corrupção continue a ser um poder oculto, um expediente mantido no mais perfeito silêncio e segredo. E essa idéia da pedagogia cívica não invalida a hipótese de que a corrupção tem que ser desocultada fora do domínio do político, porque quando se transforma em escândalo, (re)oculta-se e cancela sua potencialidade. O movimento da ordem é interrompido e o campo político retorna à sua mais perfeita normalidade. E assim, a corrupção permanece invisível, nutrida pelo esquecimento coletivo. Mas se atrelada a uma leitura moral - e não moralista - ela pode estar ali, mas sempre no horizonte das expectativas do cidadão comum.

\section{Apontamentos ao problema da desocultação da corrupção}

Das asserções produzidas nas seções anteriores, percebe-se que é fundamental rediscutir os mecanismos de comunicação política no interior da esfera pública das ordens democráticas. O modo como a corrupção é construída no discurso proferido pelos políticos profissionais e pela mídia implica um processo de tendências de crises políticas permanentes, em que o resultado não é o aprimoramento dos mecanismos de controle, mas um processo em que a corrupção, mesmo subliminar, permaneça incrustada no discurso da sociedade, criando um descontentamento generalizado que se expressa, sobretudo, como desconfiança generalizada em relação aos governos, aos parlamentos e ao judiciário.

O resultado é uma crise da democracia, em que cidadãos perdem a confiança nas instituições políticas, acarretando uma crise de legitimidade que está na base da política contemporânea (FILGUEIRAS, 2007b). A vigilância exercida pela mídia em relação à política é fundamental para o controle da corrupção. Porém, a forma como são veiculados os casos de corrupção e os interesses relacionados à sua prática enviesam a análise de sua abrangência na esfera pública. A corrupção é fato da política e com ela terá sempre que conviver. No entanto, a comunidade dos intérpretes da corrupção a percebe como algo nocivo e perigoso à política, devendo ser erradicada como prática. Essencialmente, a mídia e a própria esfera de representação política, via partidos e burocracias, constroem uma idéia de corrupção assentada sobre uma histeria ética que não produz resultados práticos para seu controle.
Dessa forma, o exercício reflexivo realizado no âmbito deste artigo aponta para o fato de que a abrangência da corrupção nas democracias contemporâneas acarreta um processo de crise de legitimação, em que a corrupção se torna uma constante no discurso político da mídia, de políticos profissionais e da burocracia do Estado. A histeria ética derivada desse processo corrói a democracia, de maneira que afasta o cidadão comum da esfera pública, formando um contexto de crescente apatia e indiferença em relação à política.

Ao persistir o fenômeno da desocultação da corrupção, as democracias correm o risco de uma permanente instabilidade e incerteza. $\mathrm{O}$ resultado desse processo de comunicação política é criar uma erosão dos marcos institucionais da democracia. Ao contrário de exercer um processo pedagógico sobre a cidadania, os processos de comunicação política, no que tange à corrupção, colaboram para seu enfraquecimento. Dessa forma, é fundamental uma atividade mais reflexiva por parte da mídia e dos partidos na esfera pública. Caso contrário, a democracia será vítima da apatia, do privatismo e da indiferença de uma cultura política em que as delinquências do homem público são vistas como naturais e cotidianas no interior da esfera pública.

\section{REFERÊNCIAS}

ARENDT, H. Entre o passado e o futuro. São Paulo: Perspectiva, 1972.

BOURDIEU, P. A economia das trocas simbólicas. São Paulo: Perspectiva, 2001.

O poder simbólico. Rio de Janeiro: Bertrand Brasil, 2005.

FILGUEIRAS, F. A corrupção do estado: perspectivas teóricas e seu processo social. Utopia y práxis latinoamericana, Maracaíbo, v. 11, n. 34, p. 11-34, 2006.

A corrupção e a patogenia das instituições políticas. 2007a. 275 f. Tese (Doutorado em Ciência Política) - Instituto Universitário de Pesquisas do Rio de Janeiro, Rio de Janeiro, 2007a.

República, confiança e sociedade. Dados - Revista de Ciências Sociais, Rio de Janeiro, v. 50, n. 4, p. 863-897, 2007b. 
GARAPON, A. O juiz e a democracia. Rio de Janeiro: Revan, 2001.

HABERMAS, J. A crise de legitimação no capitalismo tardio. Rio de Janeiro: Tempo Brasileiro, 2002.

Mudança estrutural da esfera pública. Rio de Janeiro: Tempo Brasileiro, 2003.

Verdade e justificação: ensaios filosóficos. São Paulo: Loyola, 2004.

LESSA, R. Da corrupção, do despotismo e de algumas incertezas: uma perspectiva cética. In: LESSA, R. Agonia, aposta e ceticismo. Belo Horizonte: Ed. da UFMG, 2003.

SHERMAN, L. The mobilization of the scandal. In: HEIDENHEIMER, A. et al. Political corruption: a handbook. New Brunswick: Transaction Publishers, 1990.
THOMPSON, J. B. O escândalo político: poder e visibilidade na era da mídia. Petrópolis: Vozes, 2002.

WEBER, M. A política como vocação. In: GERTH, H. H.; MILLS, C. W. (Org.). Ensaios de sociologia. Rio de Janeiro: LTC, 2002. p. 325-328.

Recebido: 07/04/2008

Received: 04/07/2008

Aprovado: $25 / 05 / 2008$

Approved: 05/25/2008 